\title{
Dapagliflozin - a key pawn on the new guidelines chessboard
}

\author{
Corresponding author: \\ Jacek Kubica, Collegium Medicum \\ Nicolaus Copernicus University, \\ Bydgoszcz, Poland, \\ e-mail: jkubica@cm.umk.pl
}

Medical Research Journal 2021; Volume 6, Number 4, 342-350 10.5603/MRJ.a2021.0056 Copyright (C) 2021 Via Medica ISSN 2451-2591 e-ISSN 2451-4101

\begin{abstract}
Treatment of patients with heart failure and reduced left ventricular ejection fraction (HFrEF) aims to reduce mortality, prevent rehospitalizations due to heart failure (HF) exacerbation, and improve the clinical status, functional capacity, and quality of life. All these goals were achieved in the DAPA-HF trial. In this trial, the reduction in the primary outcome, defined as a composite of worsening of HF or cardiovascular death, was achieved in patients receiving dapagliflozin [hazard ratio (HR) 0.74 ; 95\% confidence interval (Cl) 0.65-0.85; p < 0.001) as compared with placebo. In addition, the beneficial effect of dapagliflozin on the primary outcome was generally consistent across prespecified subgroups regardless of baseline treatment, diagnosis of diabetes, or left ventricular ejection fraction (LVEF).

Data from multiple countries was obtained in the CVD-REAL study. The use of different sodium-glucose co-transporter 2 (SGLT2) inhibitors, versus other glucose-lowering drugs, was associated with lower rates of hospitalization for HF (HR 0.61; 95\% Cl 0.51-0.73; p < 0.001) and death (HR 0.49; 95\% Cl 0.41-0.57; $p<0.001)$. These findings were confirmed in the CVD-REAL-2 study.

The exceptional clinical benefits of SGLT2 inhibitors applied on top of the previously guideline-recommended treatment in patients with chronic HFrEF led to fundamental changes in the recommended treatment strategy proposed in the 2016 European Society of Cardiology (ESC) guidelines for the diagnosis and treatment of acute and chronic HF.

To conclude, the new treatment algorithm for HFrEF is based on the findings of many groundbreaking trials. However, it is the results of trials with SGLT2 inhibitors, applied in patients with HFrEF on top of the optimal treatment including an implantable cardioverter-defibrillator and/or cardiac resynchronization therapy, that have fundamentally changed the strategy of treatment.

Key words: heart failure, SGLT2i, dapagliflozin
\end{abstract}

Med Res J 2021; 6 (4): 342-350

\section{Introduction}

\section{Mechanisms of action of SGLT2 inhibitors}

Reducing glucose and sodium reabsorption in proximal tubules caused by sodium-glucose co-transporter 2 (SGLT2) inhibitors increases urinary glucose and sodium excretion, resulting in enhanced osmotic diuresis and consequently leads to diminished plasma volume and reduced preload. A concomitant decrease in arterial stiffness and blood pressure leads to the afterload reduction [1-3]. Moreover, the beneficial effect of SGLT2 inhibitors on left ventricular (LV) systolic (increase in LVEF) and diastolic (decrease in LV filling pressure) functions was shown in patients with heart failure $(\mathrm{HF})$, leading to simultaneous lowering of plasma brain natriuretic peptide concentration [4]. In addition, the hemodynamic effects of SGLT2 inhibition can be seen in both hyper- and euglycemic patients [1, 5]. Inhibition of sodium absorption delivers an excess of sodium to the macula densa, thereby triggering the release of vasoconstrictive molecules, which results in vasoconstriction of the glomerular afferent arterioles and the subsequent reduction of the glomerular filtration rate (GFR) (Fig. 1). It should be emphasized that glucosuria and GFR reduction should be regarded as the mechanism of action of SGLT2 inhibitors, not as side effects [2, $3,6]$. These mechanisms of action of SGLT2 inhibitors make them an excellent therapeutic option for patients with HF, providing an additional nephroprotective effect. 


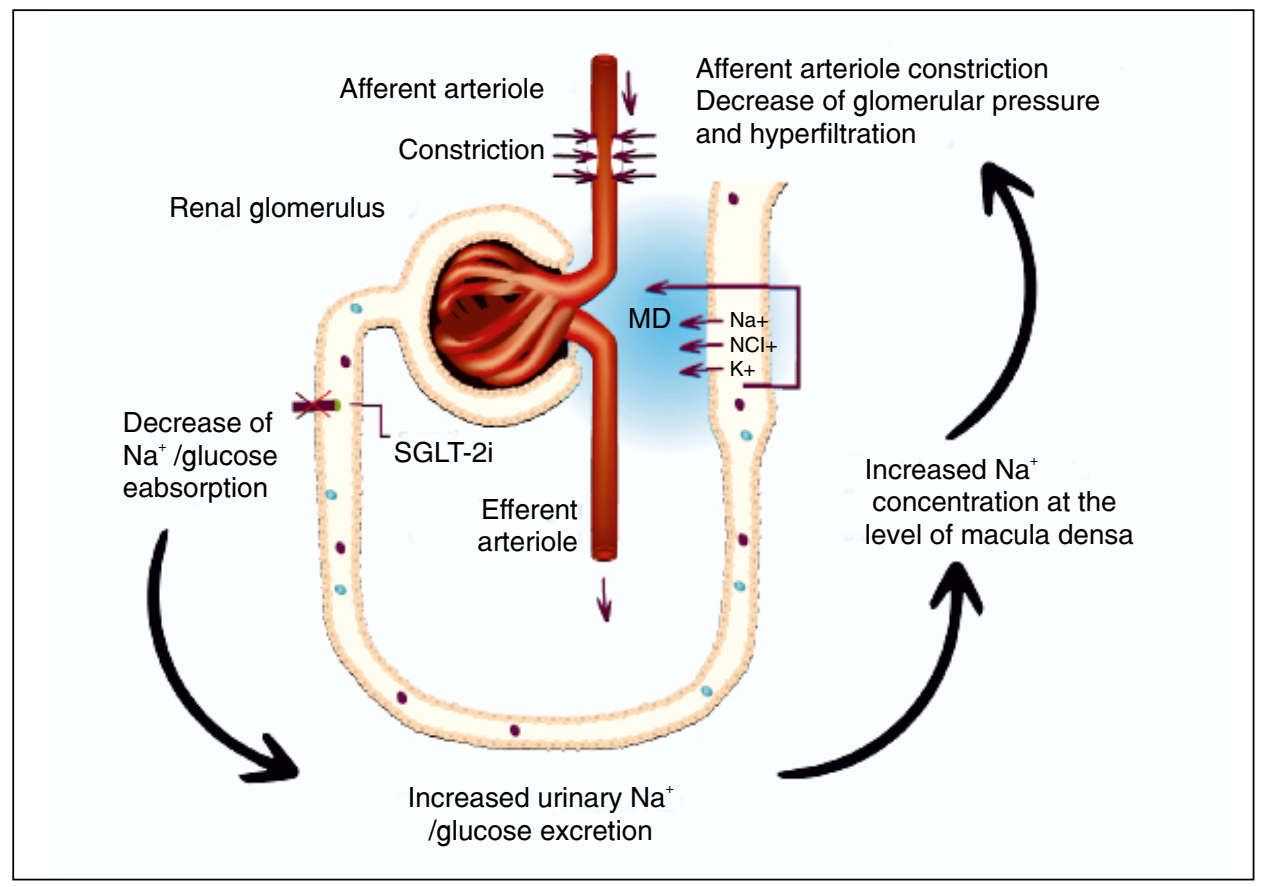

Figure 1. Pivotal mechanisms of SGLT2 inhibitors action. MD — macula densa; SGLT-2i — sodium-glucose co-transporter 2 inhibitors

\section{Material and methods}

\section{The DAPA-HF trial}

Treatment of patients with HF aims to reduce mortality, prevent rehospitalizations due to HF exacerbation, and improve the clinical status, functional capacity, and quality of life [7]. All these goals were achieved in the Dapagliflozin and Prevention of Adverse Outcomes in Heart Failure (DAPA-HF) trial (Fig. 2) [8].

In this trial, 4744 patients with HF (NYHA II-IV) with reduced ejection fraction $(<40 \%$ ) were randomized to receive dapagliflozin $10 \mathrm{mg} /$ day or placebo, on top of optimal standard therapy for HF $[9,10]$. Patients with $(45 \%)$ or without diabetes $(55 \%)$ were enrolled. A significant reduction in the primary outcome, defined as a composite of worsening of HF (hospitalization or an urgent visit resulting in intravenous therapy for HF) or cardiovascular death, was achieved in patients receiving dapagliflozin (HR $0.74 ; 95 \% \mathrm{Cl} 0.65-0.85$; $p<0.001$ ) (Fig. 3). Each of the components of the primary outcome was also reduced - by $30 \%$ [HR 0.70 (95\% Cl 0.59-0.83); $\mathrm{p}<0.0001]$ and 18\% [HR $0.82(95 \% \mathrm{Cl} 0.69-0.98) ; \mathrm{p}=0.029]$, respectively. Moreover, the reduction of all-cause mortality was also observed [HR $0.83(95 \% \mathrm{Cl} 0.71-0.97$ ]; $p=0.022$ ] in subjects treated with dapagliflozin [9]. It should be highlighted that patients with or without diabetes appeared to benefit to the same extent. The benefit of dapagliflozin could be seen soon after treatment initiation, and the number needed to treat during the follow-up period of 18.2 months was only 21 [8, 11]. The beneficial effect of dapagliflozin on the primary outcome was generally consistent across prespecified subgroups regardless of baseline treatment, diagnosis of diabetes, and LVEF [12]. However, patients in NYHA functional class III or IV appeared to have reduced benefit than those in class II [8, 13]. The efficacy and safety of dapagliflozin were also similar irrespectively of the diuretic dosage [14], the use of glucose-lowering therapy, or its type, in patients with diabetes and HF and reduced ejection fraction (HFrEF) [15]. Moreover, the benefit of dapagliflozin was almost identical, regardless of baseline sacubitril/valsartan use, suggesting that these 2 therapies have complementary biological mechanisms of action [16]. Longer HF duration was associated with an increased rate of the primary outcome. The absolute benefit of dapagliflozin was greatest in longest-duration HF. However, the relative benefit of dapagliflozin was consistent across the whole spectrum of HF duration. The hazard ratio for the primary outcome of HF duration of $\geq 2$ to $\leq 12$ months was 0.86 (0.63$1.18),>1$ to 2 years $0.95(0.64-1.42),>2$ to 5 years $0.74(0.57-0.96)$, and $>5$ years $0.64(0.53-0.78)$; $\mathrm{p}$ for interaction $=0.26[17]$. 


\begin{tabular}{l}
$\begin{array}{l}\text { Goals of treatment for } \\
\text { patients with HFrEF }\end{array}$ \\
$\begin{array}{l}\text { Reduction in mortality } \\
\text { - Cardiovascular mortality } \\
\text { dapagliflozin vs. placebo }\end{array}$ \\
• All cause mortality \\
\hline $\begin{array}{l}\text { Prevention of recurrent hospitalizations } \\
\text { due to HF worsening }\end{array}$ \\
\hline $\begin{array}{l}\text { Improvement in clinical status, } \\
\text { functional capacity, and quality of live } \\
\text { - Deterioration }\end{array}$ \\
• Small improvement \\
• Moderate improvement
\end{tabular}

Figure 2. Goals of treatment for patients with HFrEF according to $2021 \mathrm{ECS}$ guidelines in relation to results of the DAPA-HF trial *HF-related symptoms assessed with the Kansas City Cardiomyopathy Questionnaire; DAPA-HF — Dapagliflozin and Prevention of Adverse Outcomes in Heart Failure; HFrEF — heart failure and reduced ejection fraction

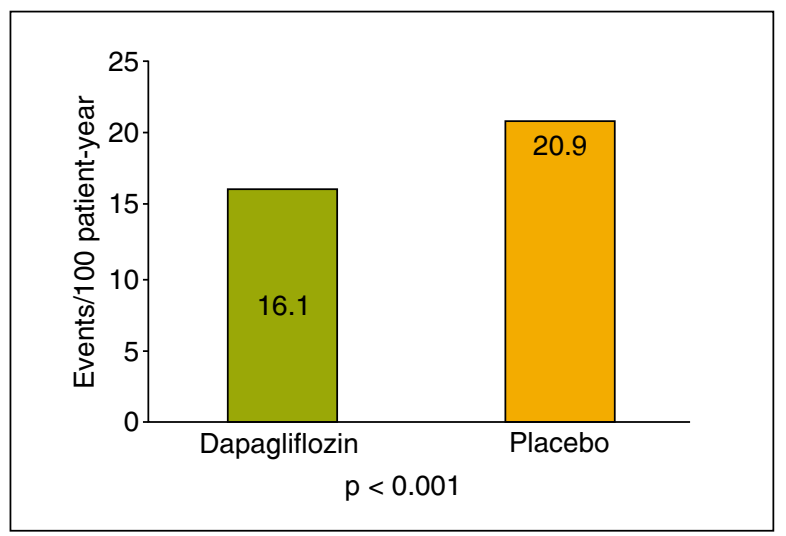

Figure 3. The primary outcome (a composite of worsening of heart failure or cardiovascular death) of the DAPA-HF trial. DAPA-HF — Dapagliflozin and Prevention of Adverse Outcomes in Heart Failure

The use of dapagliflozin also resulted in improvement of symptoms of HF, as measured on the Kansas City Cardiomyopathy Questionnaire (KCCQ) - a validated, self-administered instrument that quantifies HF-related symptoms, function, and quality of life [18]. Fewer patients on dapagliflozin had a deterioration in KCCQ total symptom score [odds ratio (OR) 0.84 (95\%
Cl 0.78-0.90); $p<0.0001]$. More patients had at least small [OR $1.15(95 \% \mathrm{Cl} 1.08-1.23) ; \mathrm{p}<0.0001$ ], moderate [OR 1.15 (95\% Cl 1.08-1.22); $\mathrm{p}<0.0001$ ], and large improvements [OR 1.14 (95\% Cl 1.07-1.22); $p<0.0001$ ] [18].

The high efficacy of dapagliflozin was accompanied by a favorable safety profile and very good drug tolerance. Serious adverse events related to volume depletion occurred in 29 patients $(1.2 \%)$ in the dapagliflozin group and in 40 patients (1.7\%) in the placebo group $(p=0.23)$. Serious renal adverse events occurred in 38 patients $(1.6 \%)$ in the dapagliflozin group and in 65 patients $(2.7 \%)$ in the placebo group $(p=0.009)$. Major hypoglycemia was very rare $(0.2 \%$ in both arms), as was diabetic ketoacidosis $(0.1 \%)$ in patients on dapagliflozin, and both of these adverse events occurred only in patients with diabetes [8]. The rate of study treatment discontinuation due to adverse events was similar in both arms. It occurred in 111 patients (4.7\%) in the dapagliflozin group and 116 patients (4.9\%) in the placebo group [8].

\section{Scientific evidence supporting the clinical efficacy of SGLT2 inhibitors}

The DEFINE-HF study (Dapagliflozin Effects on Biomarkers, Symptoms and Functional Status in Patients 


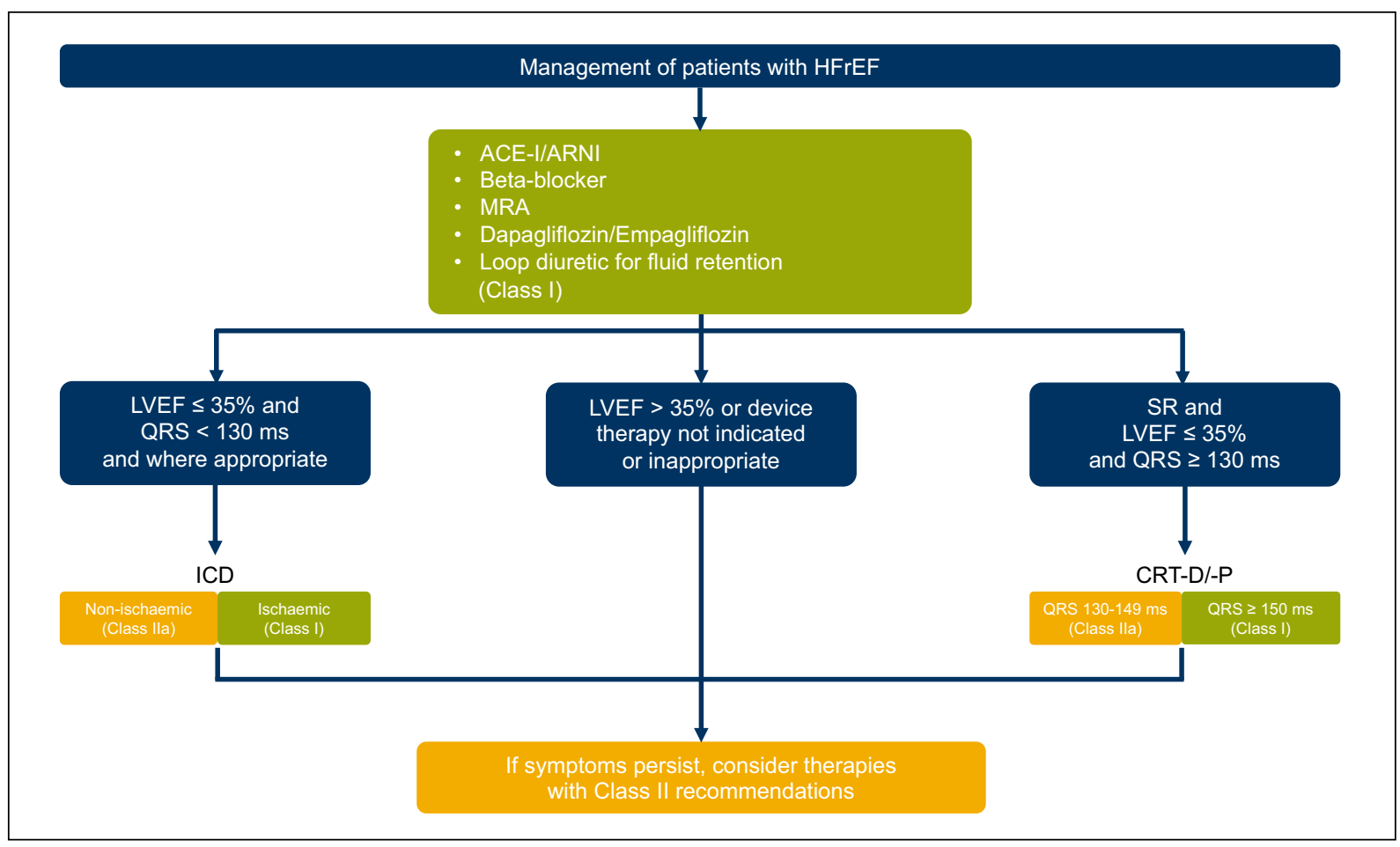

Figure 4. A new simplified treatment algorithm for HFrEF — adapted from 2021 ESC guidelines [7]. ACE-I — angiotensinconverting enzyme inhibitors; ARNI — angiotensin receptor-neprilysin inhibitor; CRT-D — cardiac resynchronization therapy with defibrillator; CRT-P — cardiac resynchronization therapy with pacemaker; ESC - European Society of Cardiology; HFrEF — heart failure and reduced ejection fraction; ICD — implantable cardioverter-defibrillator; LVEF — left ventricular ejection fraction; MRA — mineralocorticoid receptor antagonists; SR — sinus rhythm

with HF with Reduced Ejection Fraction) demonstrated a beneficial effect of dapagliflozin, with clinically significant improvements in disease-specific health status and natriuretic peptides levels in patients with HFrEF, with and without diabetes, receiving optimal medical therapy [19].

A meta-analysis of the two large-scale trials - DAPA-HF and EMPEROR-Reduced -was performed to assess the effects of SGLT2 inhibitors on cardiovascular outcomes in patients with HFrEF with or without diabetes. The estimated effect of SGLT2 inhibition was a $13 \%$ reduction in all-cause death (HR 0.87 ; 95\% $\mathrm{Cl} 0.77-0.98 ; \mathrm{p}=0.018)$ and $14 \%$ reduction in cardiovascular death (HR 0.86; 95\% Cl 0.76-0.98; $p=0.027$ ) [20]. The scale of risk reduction of cardiovascular death was inconsistent in both trials, as the significant reduction was only achieved in the DAPA-HF trial. The relative reduction in cardiovascular death was $18 \%$ (HR 0.82; 95\% Cl 0.69-0.98) in the DAPA-HF trial (with dapagliflozin) and 8\% (HR 0.92; 95\% $\mathrm{Cl}$ 0.75-1.12) in the EMPEROR-Reduced trial (with empagliflozin) [20]. A 26\% reduction in the combined risk of cardiovascular death or first hospitalization for HF (HR 0.74; 95\% Cl 0.68-0.82; $p<0.0001$ ) was seen in patients treated with dapagliflozin or empagliflozin versus placebo. Moreover, the composite renal endpoint was also reduced (HR 0.62; 95\% Cl 0.43-0.90; $\mathrm{p}=0.013)[20]$.

Data from multiple countries obtained in the CVD-REAL study (Comparative Effectiveness of Cardiovascular Outcomes in New Users of SGLT2 Inhibitors) allowed comparison of the risk for HF hospitalization and death in patients with diabetes type 2 who were new users of SGLT2 inhibitors versus other glucose-lowering drugs in real-world practice [21]. The data were collected via medical claims, primary care/hospital records, and national registries from the United States, Norway, Denmark, Sweden, Germany, and the United Kingdom. After propensity matching for SGLT2 inhibitors initiation, the analysis was performed in 309056 patients (154 528 patients in each treatment group). Patients on canagliflozin (53\%), dapagliflozin (42\%), and empagliflozin (5\%) were included. The use of SGLT2 inhibitors, versus other glucose-lowering drugs, was associated with lower rates of hospitalization for HF (HR 0.61; 95\% $\mathrm{Cl} 0.51-0.73 ; \mathrm{p}<0.001$ ) and death (HR 0.49; 95\% Cl $0.41-0.57 ; p<0.001)$. The lower rates of death and hospitalization for HF associated with SGLT2 inhibitors are likely class-related, as there was no significant heterogeneity across countries, despite considerable 
geographic variations in the use of specific SGLT2 inhibitors $(\approx 76 \%$ canagliflozin in the United States and $\approx 92 \%$ dapagliflozin in Europe) [21].

The CVD-REAL-2 study was a continuation of the CVD-REAL project. It was conducted across 6 countries in the Asia Pacific, the Middle East, and North American regions [22]. After propensity-matching, there were 235064 episodes of treatment initiation in each group (SGLT2 inhibitors versus other glucose-lowering drugs). Dapagliflozin, empagliflozin, ipragliflozin, canagliflozin, tofogliflozin, and luseogliflozin accounted for $75 \%, 9 \%, 8 \%, 4 \%, 3 \%$, and $1 \%$ of exposure time in the SGLT2 inhibitors group, respectively. The use of SGLT2 inhibitors was associated with a lower risk of death (HR 0.51 ; 95\% Cl 0.37-0.70; $\mathrm{p}<0.001)$, hospitalization for HF (HR 0.64; 95\% Cl $0.50-0.82 ; \mathrm{p}=0.001$ ), and stroke (HR 0.68; $95 \% \mathrm{Cl}$ $0.55-0.84 ; p<0.001)$. The results were directionally consistent across countries and patient subgroups, including those with and without cardiovascular disease [22].

\section{The key role of SGLT2 inhibitors in the ESC guidelines}

The 2016 ESC guidelines for the diagnosis and treatment of acute and chronic HF recommended a gradual introduction of key drugs into therapy, depending on their effect on clinical symptoms [23]. The exceptional clinical benefits of SGLT2 inhibitors applied on top of the previously guideline-recommended treatment [23] in patients with chronic HFrEF, regardless of coexistence of diabetes mellitus [8, 24], led to fundamental changes in the recommended strategy of treatment $[25,26]$.

A new simplified treatment algorithm for HFrEF (Fig. 4) and the addition of a phenotype-specific treatment algorithm for HFrEF (Fig. 5) are pivotal new concepts introduced in the new 2021 ESC guidelines for the diagnosis and treatment of acute and chronic HF [7]. According to the new algorithm, the first-line therapy should include four elements: angiotensin-converting enzyme inhibitors (ACE-I) or an angiotensin receptor-neprilysin inhibitor (ARNI), beta-blockers (BB), mineralocorticoid receptor antagonists (MRA), and SGLT2i (dapagliflozin or empagliflozin) unless the drugs are contraindicated or not tolerated. ACE-I should be replaced with $A R N I$ in patients who remain symptomatic on ACE-I, beta-blocker, and MRA. However, instead of ACE-I, ARNI may also be applied as first-line therapy. Angiotensin-receptor blockers should be used in patients intolerant to ACE-I or ARNI [7]. The recommended 4-component (ACE-I/ARNI + BB + MRA + SGLT2i) first-line therapy proved to reduce the risk of HF hospitalization and death [8, 20, 24].

The new ESC guidelines emphasize the key role of multidisciplinary team management to implement HF management programs to prevent and treat chronic HF [7]. These programs, designed to improve clinical outcomes, should cover adequate preparation for hospital discharge and the further collaboration between members of the multidisciplinary team and patients. Furthermore, the organization of HF management programs should be adapted to the local healthcare system, available resources, administrative policies, and tailored to the patient's needs [7]. Finally, implementing these recommendations implies the need to monitor the effectiveness of the actions taken using validated diagnostic tools to assess the readiness for discharge from the hospital, the implementation of the therapeutic plan, and functioning in chronic disease [27-36]. 


\section{Management of HFrEF}

To reduce mortality - for all patients

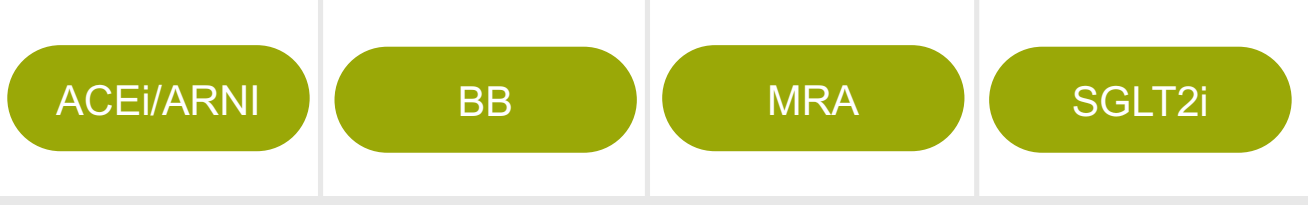

To reduce HF hospitalization/mortality - for selected patients

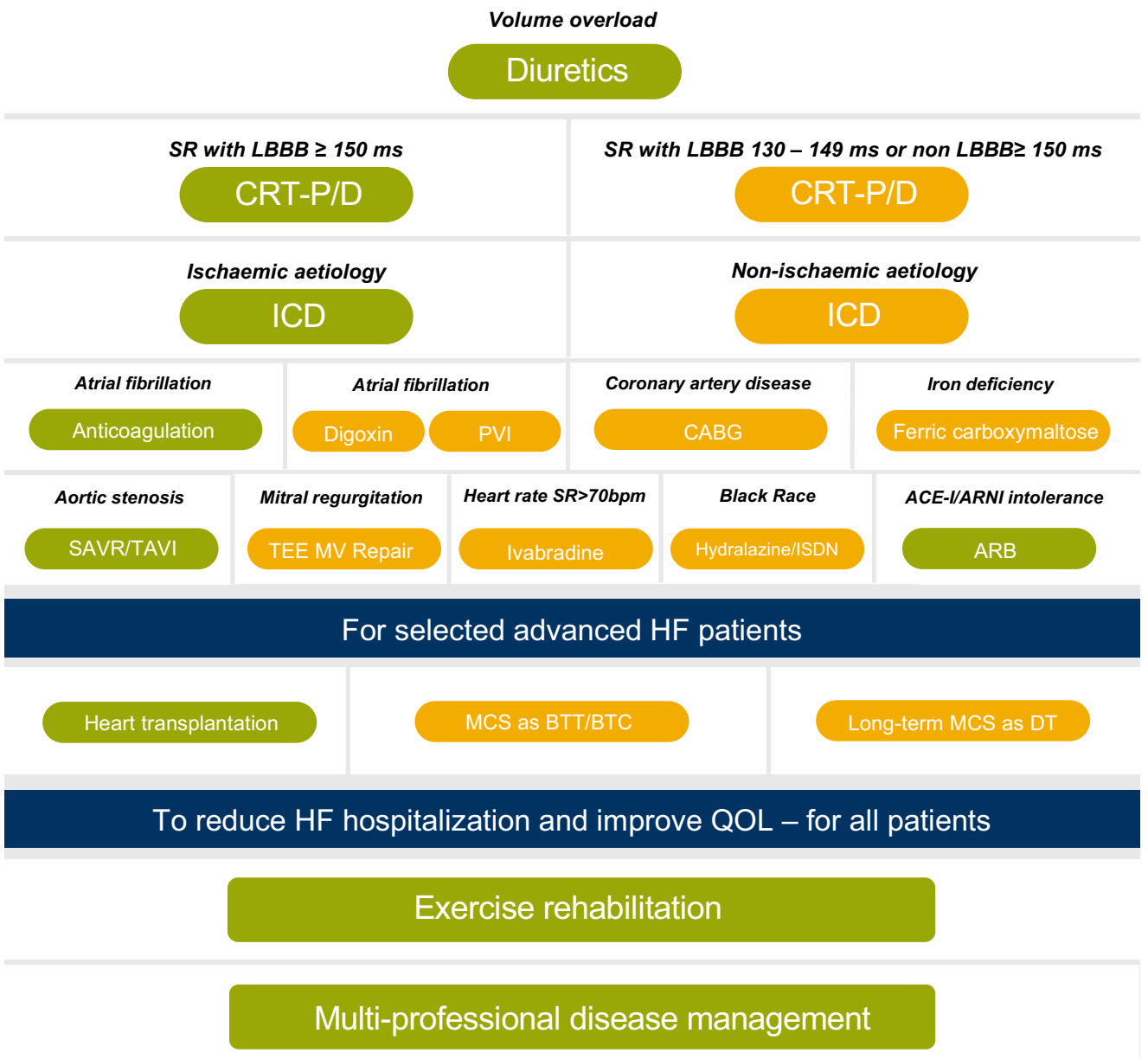

Figure 5. A phenotype-specific treatment algorithm for HFrEF - adapted from 2021 ESC guidelines [7]. ACE-I — angiotensinconverting enzyme inhibitors; ARB - angiotensin receptor blocker; ARNI - angiotensin receptor-neprilysin inhibitor; BB - beta-blockers; BTC - bridge to candidacy; BTT — bridge to transplantation; CABG - coronary artery bypass grafting; CRT-D — defibrillator with cardiac resynchronization therapy; CRT-P — pacemaker with cardiac resynchronization therapy; DT — destination therapy; ESC — the European Society of Cardiology; HF — heart failure; HFrEF — heart failure and reduced ejection fraction; ICD - implantable cardioverter-defibrillator; LBBB - left bundle branch block; LVEF - left ventricular ejection fraction; MCS - mechanical circulatory support; MRA - mineralocorticoid receptor antagonists; QoL - quality of life; SGLT2i - sodium-glucose co-transporter 2 inhibitors; SR - sinus rhythm; TEE — transoesophageal echocardiography 


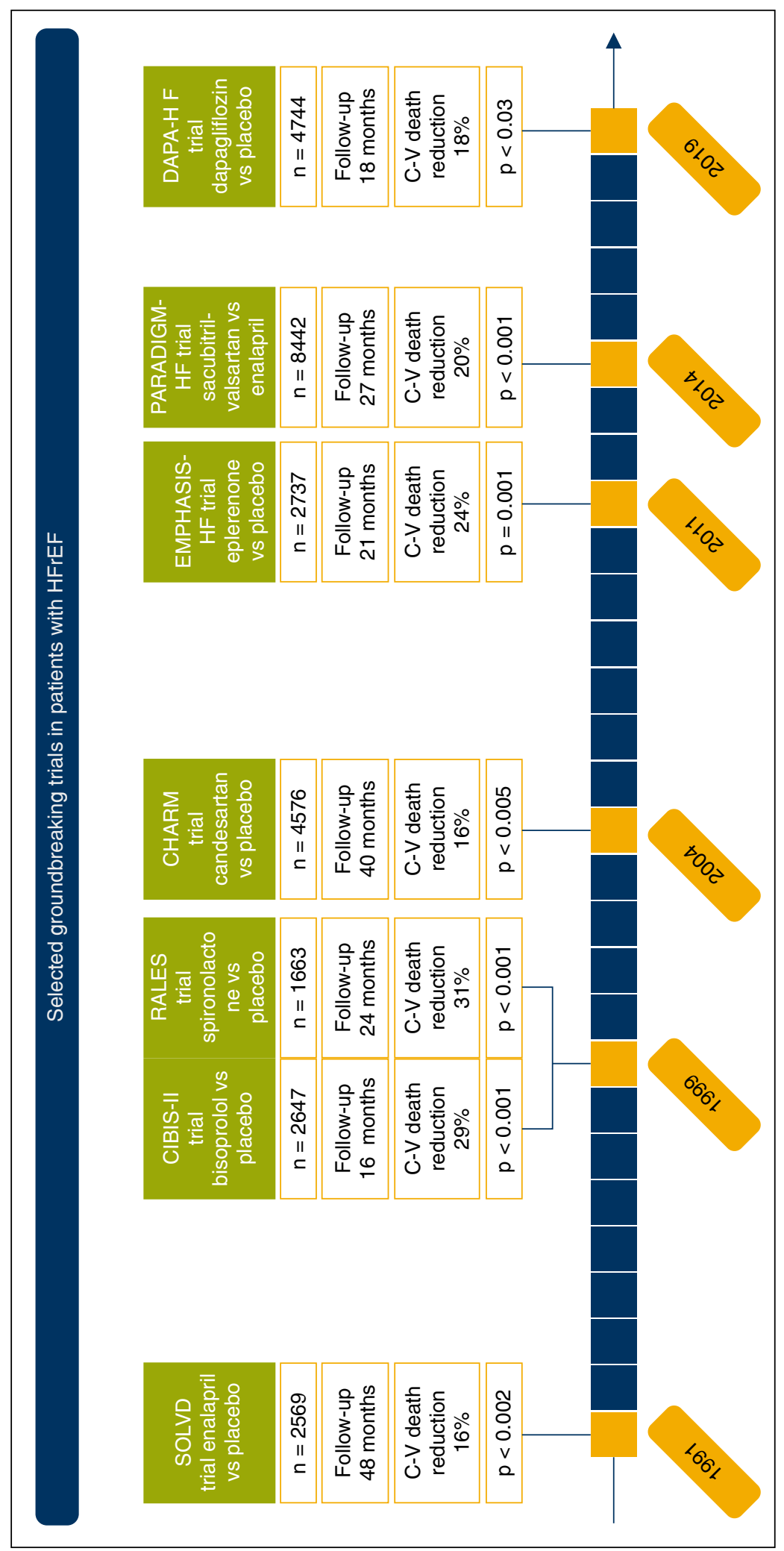

Figure 6. Selected groundbreaking trials in patients with HFrEF 


\section{Conclusion}

In conclusion, the new treatment algorithm for HFrEF is based on the findings of many groundbreaking trials [8, 24, 37-44] (Fig. 6). However, it is the results of trials with SGLT2 inhibitors, applied in patients with HFrEF on top of the optimal treatment including an implantable cardioverter-defibrillator and/or cardiac resynchronization therapy, that have fundamentally changed the strategy of treatment.

\section{Conflict of interest: None.}

\section{Funding: None.}

\section{References}

1. Lytvyn Y, Bjornstad P, Udell JA, et al. Sodium-glucose cotransporter-2 inhibition in heart failure: potential mechanisms, clinical applications, and summary of clinical trials. Circulation. 2017; 136(17): 1643-1658, doi: 10.1161/CIRCULATIONAHA.117.030012, indexed in Pubmed: 29061576

2. Dekkers CCJ, Sjöström CD, Greasley PJ, et al. Effects of the sodium-glucose co-transporter-2 inhibitor dapagliflozin on estimated plasma volume in patients with type 2 diabetes. Diabetes Obes Metab. 2019; 21(12): 2667-2673, doi: 10.1111/dom.13855, indexed in Pubmed: 31407856.

3. Kubica J, Kubica A, Grzelakowska K, et al. Inhibitors of sodium-glucose transport protein 2: A new multidirectional therapeutic option for heart failure patients. Cardiol J. 2021 [Epub ahead of print], doi: 10.5603/CJ.a2021.0133, indexed in Pubmed: 34708866.

4. Soga F, Tanaka H, Tatsumi K, et al. Impact of dapagliflozin on left ventricular diastolic function of patients with type 2 diabetic mellitus with chronic heart failure. Cardiovasc Diabetol. 2018; 17(1): 132, doi: 10.1186/s12933-018-0775-Z, indexed in Pubmed: 30296931.

5. Ferrannini E, Muscelli E, Frascerra S, et al. Metabolic response to sodium-glucose co-transporter 2 inhibition in type 2 diabetic patients. J Clin Invest. 2014; 124(2): 499-508, doi: 10.1172/JCI72227, indexed in Pubmed: 24463454.

6. Carlström M, Wilcox CS, Arendshorst WJ. Renal autoregulation in health and disease. Physiol Rev. 2015; 95(2): 405-511, doi: 10.1152/physrev.00042.2012, indexed in Pubmed: 25834230.

7. McDonagh TA, Metra M, Adamo M, et al. ESC Scientific Document Group. 2021 ESC Guidelines for the diagnosis and treatment of acute and chronic heart failure. Eur Heart J. 2021; 42(36): 3599-3726, doi: 10.1093/eurheart//ehab368, indexed in Pubmed: 34447992.

8. McMurray JJV, Solomon SD, Inzucchi SE, et al. DAPA-HF Trial Committees and Investigators. Dapagliflozin in patients with heart failure and reduced ejection fraction. N Engl J Med. 2019; 381(21): 1995-2008, doi: 10.1056/NEJMoa1911303, indexed in Pubmed: 31535829.

9. McMurray JJV, DeMets DL, Inzucchi SE, et al. DAPA-HF Committees and Investigators. The Dapagliflozin And Prevention of Adverse-outcomes in Heart Failure (DAPA-HF) trial: baseline characteristics. Eur J Heart Fail. 2019; 21(11): 1402-1411, doi: 10.1002/ejhf.1548, indexed in Pubmed: 31309699.

10. McMurray JJV, DeMets DL, Inzucchi SE, et al. DAPA-HF Committees and Investigators. A trial to evaluate the effect of the sodium-glucose co-transporter 2 inhibitor dapagliflozin on morbidity and mortality in patients with heart failure and reduced left ventricular ejection fraction (DAPA-HF). Eur J Heart Fail. 2019; 21(5): 665-675, doi: 10.1002/ejhf.1432, indexed in Pubmed: 30895697.

11. Bhatt DL, Verma S, Braunwald E. The DAPA-HF trial: a momentous victory in the war against heart failure. Cell Metab. 2019; 30(5): 847-849, doi: 10.1016/..cmet.2019.10.008, indexed in Pubmed: 31693879

12. Dewan P, Solomon SD, Jhund PS, et al. DAPA-HF Investigators and Committees. Efficacy and safety of sodium-glucose co-transporter 2 inhibition according to left ventricular ejection fraction in DAPA-HF. Eur J Heart Fail. 2020; 22(7): 1247-1258, doi: 10.1002/ejhf.1867, indexed in Pubmed: 32539224.
13. Petrie MC, Verma S, Docherty KF, et al. Effect of dapagliflozin on worsening heart failure and cardiovascular death in patients with heart failure with and without diabetes. JAMA. 2020; 323(14): 1353-1368, doi: 10.1001/jama.2020.1906, indexed in Pubmed: 32219386.

14. Jackson AM, Dewan P, Anand IS, et al. Dapagliflozin and diuretic use in patients with heart failure and reduced ejection fraction in DAPA-HF. Circulation. 2020; 142(11): 1040-1054, doi: 10.1161/CIRCULATIONAHA.120.047077, indexed in Pubmed: 32673497.

15. Docherty KF, Jhund PS, Bengtsson O, et al. DAPA-HF Investigators and Committees. Effect of dapagliflozin in DAPA-HF according to background glucose-lowering therapy. Diabetes Care. 2020; 43(11): 2878-2881, doi: 10.2337/dc20-1402, indexed in Pubmed: 33082245.

16. Solomon SD, Jhund PS, Claggett BL, et al. Effect of dapagliflozin in patients with hfref treated with sacubitril/valsartan: the DAPA-HF trial. JACC Heart Fail. 2020; 8(10): 811-818, doi: 10.1016/j.jchf.2020.04.008, indexed in Pubmed: 32653447

17. Yeoh SE, Dewan P, Jhund PS, et al. DAPA-HF Investigators and Committees. Patient characteristics, clinical outcomes, and effect of dapagliflozin in relation to duration of heart failure: is it ever too late to start a new therapy? Circ Heart Fail. 2020; 13(12): e007879, doi: 10.1161/CIRCHEARTFAILURE.120.007879, indexed in Pubmed: 33164553.

18. Kosiborod MN, Jhund PS, Docherty KF, et al. Effects of dapagliflozin on symptoms, function, and quality of life in patients with heart failure and reduced ejection fraction: results from the DAPA-HF trial. Circulation. 2020; 141(2): 90-99, doi: 10.1161/CIRCULATIONAHA.119.044138, indexed in Pubmed: 31736335

19. Nassif ME, Windsor SL, Tang F, et al. Dapagliflozin effects on biomarkers, symptoms, and functional status in patients with heart failure with reduced ejection fraction: the DEFINE-HF trial. Circulation. 2019; 140(18): 1463-1476, doi: 10.1161/CIRCULATIONAHA.119.042929, indexed in Pubmed: 31524498

20. Zannad F. Ferreira JP, Pocock SJ, et al. SGLT2 inhibitors in patients with heart failure with reduced ejection fraction: a meta-analysis of the EMPEROR-Reduced and DAPA-HF trials. Lancet. 2020; 396(10254): 819-829, doi: 10.1016/S0140-6736(20)31824-9, indexed in Pubmed: 32877652

21. Kosiborod M, Cavender MA, Fu AZ, et al. CVD-REAL Investigators and Study Group*. Lower risk of heart failure and death in patients initiated on sodium-glucose cotransporter-2 inhibitors versus other glucose-lowering drugs: the CVD-REAL study (comparative effectiveness of cardiovascular outcomes in new users of sodium-glucose cotransporter-2 inhibitors). Circulation. 2017; 136(3): 249-259, doi: 10.1161/CIRCULATIONAHA.117.029190, indexed in Pubmed: 28522450.

22. Kosiborod M, Lam CSP, Kohsaka S, et al. CVD-REAL Investigators and Study Group. Cardiovascular events associated with SGLT-2 inhibitors versus other glucose-lowering drugs: the CVD-REAL 2 study. J Am Coll Cardiol. 2018; 71(23): 2628-2639, doi: 10.1016/j.jacc.2018.03.009, indexed in Pubmed: 29540325

23. Ponikowski P, Voors AA, Anker SD, et al. ESC Scientific Document Group. 2016 ESC Guidelines for the diagnosis and treatment of acute and chronic heart failure: The Task Force for the diagnosis and treatment of acute and chronic heart failure of the European Society of Cardiology (ESC)Developed with the special contribution of the Heart Failure Association (HFA) of the ESC. Eur Heart J. 2016; 37(27): 21292200, doi: 10.1093/eurheartj/ehw128, indexed in Pubmed: 27206819.

24. Packer M Anker SD, Butler J, et al. EMPEROR-Reduced Trial Investigators. Cardiovascular and renal outcomes with empagliflozin in heart failure. N Engl J Med. 2020; 383(15): 1413-1424, doi: 10.1056/NEJMoa2022190, indexed in Pubmed: 32865377.

25. Kubica J. Heart failure treatment according to the 2021 European Society of Cardiology Guidelines - experiences with SGLT2 inhibitors have changed the treatment strategy. Medical Research Journal. 2021; 6(3): 163-165, doi: 10.5603/mri.2021.0046.

26. Gager GM, von Lewinski D, Sourij H, et al. Effects of SGLT2 inhibitors on ion homeostasis and oxidative stress associated mechanisms in heart failure. Biomed Pharmacother. 2021; 143: 112169, doi: 10.1016/i biopha.2021.112169, indexed in Pubmed: 34560555

27. Buszko K, Obońska K, Michalski P, et al. The Adherence Scale in Chronic Diseases (ASCD). The power of knowledge: the key to successful patient — health care provider cooperation. Med Res J. 2016; 1(1): 37-42, doi: 10.5603/mrj.2016.0006

28. Kubica A, Kosobucka A, Michalski P, et al. The Adherence in Chronic Diseases Scale - a new tool to monitor implementation of a treatment plan. Folia Cardiol. 2017; 12(1): 19-26, doi: 10.5603/FC.a2016.0105.

29. Kubica A, Obońska K, Fabiszak T, et al. Adherence to antiplatelet treatment with P2Y12 receptor inhibitors. Is there anything we can do to improve it? A systematic review of randomized trials. Curr Med Res 
Opin. 2016; 32(8): 1441-1451, doi: 10.1080/03007995.2016.1182901, indexed in Pubmed: 27112628.

30. Kubica A, Pietrzykowski $Ł$. The therapeutic plan implementation in patients discharged from the hospital after myocardial infarction. Med Res J. 2021; 6(2): 79-82, doi: 10.5603/mri.a2021.0024.

31. Kosobucka A, Pietrzykowski $Ł$, Michalski P, et al. Impact of readiness for discharge from the hospital on the implementation of the therapeutic plan. Med Res J. 2020; 5(4): 256-264, doi: 10.5603/mrj.a2020.0047.

32. Kubica A. Self-reported questionnaires for a comprehensive assessment of patients after acute coronary syndrome. Med Res J. 2019 4(2): 106-109, doi: 10.5603/mrj.a2019.0021.

33. Kubica A, Gruchała M, Jaguszewski M, et al. Adherence to treatment - a pivotal issue in long-term treatment of patients with cardiovascular diseases. An expert standpoint. Med Res J. 2018; 2(4): 123-127, doi: 10.5603/mrj.2017.0016.

34. Kubica A, Kosobucka A, Michalski P, et al. Self-reported questionnaires for assessment adherence to treatment in patients with cardiovascula diseases. Med Res J. 2018: 2(4): 115-122, doi: 10.5603/mri.2017.0015.

35. Buszko K, Pietrzykowski $Ł$, Michalski P, et al. Validation of the Functioning in Chronic Illness Scale (FCIS). Med Res J. 2018; 3(2): 63-69, doi: 10.5603/mri.2018.0011.

36. Buszko K, Kosobucka A, Michalski P, et al. The readiness for hospital discharge of patients after acute myocardial infarction: a new self-reported questionnaire. Med Res J. 2017; 2(1): 20-28, doi: 10.5603/mrj.2017.0004

37. Yusuf S, Pitt B, Davis CE, et al. SOLVD Investigators. Effect of enalapril on survival in patients with reduced left ventricular ejection fractions and congestive heart failure. N Engl J Med. 1991; 325(5): 293-302, doi: 10.1056/NEJM199108013250501, indexed in Pubmed: 2057034

38. CIBIS-II Investigators and Committees. The Cardiac Insufficiency Bisoprolol Study II (CIBIS-II): a randomised trial. Lancet. 1999; 353(9146) 9-13, indexed in Pubmed: 10023943.
39. Pitt B, Zannad F, Remme WJ, et al. The effect of spironolactone on morbidity and mortality in patients with severe heart failure. Randomized Aldactone Evaluation Study Investigators. N Engl J Med. 1999; 341(10): 709-717, doi: 10.1056/NEJM199909023411001, indexed in Pubmed: 10471456

40. Cohn JN, Tognoni G. Valsartan Heart Failure Trial Investigators. A randomized trial of the angiotensin-receptor blocker valsartan in chronic heart failure. N Engl J Med. 2001; 345(23): 1667-1675, doi: 10.1056/NEJMoa010713, indexed in Pubmed: 11759645.

41. Poole-Wilson PA, Swedberg K, Cleland JGF et al Carvedilol Or Metoprolol European Trial Investigators. Comparison of carvedilol and metoprolol on clinical outcomes in patients with chronic heart failure in the Carvedilol Or Metoprolol European Trial (COMET): randomised controlled trial. Lancet. 2003; 362(9377): 7-13, doi: 10.1016/S01406736(03)13800-7, indexed in Pubmed: 12853193.

42. Young JB, Dunlap ME, Pfeffer MA, et al. Candesartan in Heart failure Assessment of Reduction in Mortality and morbidity (CHARM) Investigators and Committees. Mortality and morbidity reduction with Candesartan in patients with chronic heart failure and left ventricular systolic dysfunction: results of the CHARM low-left ventricular ejection fraction trials. Circulation. 2004; 110(17): 2618-2626, doi: 10.1161/01.CIR.0000146819.43235.A9, indexed in Pubmed: 15492298.

43. Zannad F, McMurray JJV, Krum H, et al. EMPHASIS-HF Study Group. Eplerenone in patients with systolic heart failure and mild symptoms. N Engl J Med. 2011; 364(1): 11-21, doi: 10.1056/NEJMoa1009492, indexed in Pubmed: 21073363.

44. McMurray JJV, Packer M, Desai AS, et al. PARADIGM-HF Investigators and Committees. Angiotensin-neprilysin inhibition versus enalapril in heart failure. N Engl J Med. 2014; 371(11): 993-1004, doi: 10.1056/NEJMoa1409077, indexed in Pubmed: 25176015 